\title{
A Structured Approach to Detecting and Treating Depression in Primary Care: VitalSign6 Project
}

\author{
Manish K. Jha, $M D^{1,2}$ \\ Bruce D. Grannemann, $M A^{1}$ \\ Joseph M. Trombello, $P b D^{1}$ \\ E. Will Clark, $M D^{1}$ \\ Sara Levinson Eidelman, MPH, \\ MSLOC $^{1}$ \\ Tiffany Lawson, MBA, $R N^{1}$ \\ Tracy L. Greer, $P b D^{1}$ \\ A. Jobn Rush, $M D^{3-5}$ \\ Madbukar H. Trivedi, $M D^{1}$
}

\begin{abstract}
PURPOSE This report describes outcomes of an ongoing quality-improvement project (VitalSign6) in a large US metropolitan area to improve recognition, treatment, and outcomes of depressed patients in 16 primary care clinics ( 6 charity clinics, 6 federally qualified health care centers, 2 private clinics serving lowincome populations, and 2 private clinics serving patients with either Medicare or private insurance).
\end{abstract}

METHODS Inclusion in this retrospective analysis was restricted to the first 25,000 patients (aged $\geq 12$ years) screened with the 2-item Patient Health Questionnaire (PHQ-2) in the aforementioned quality-improvement project. Further evaluations with self-reports and clinician assessments were recorded for those with positive screen (PHQ-2 >2). Data collected from August 2014 though November 2016 were available at 3 levels: (1) initial PHQ-2 $(n=25,000)$, (2) positive screen $(n=4,325)$, and (3) clinician-diagnosed depressive disorder with 18 or more weeks of enrollment $(n=2,160)$.

RESULTS Overall, $17.3 \%(4,325 / 25,000)$ of patients screened positive for depression. Of positive screens, $56.1 \%(2,426 / 4,325)$ had clinician-diagnosed depressive disorder. Of those enrolled for 18 or more weeks, $64.8 \%$ were started on measurement-based pharmacotherapy and $8.9 \%$ referred externally. Of the 1,400 patients started on pharmacotherapy, $45.5 \%, 30.2 \%, 12.6 \%$, and $11.6 \%$ had 0 , 1,2 , and 3 or more follow-up visits, respectively. Remission rates were $20.3 \%$ (86/423), 31.6\% (56/177), and 41.7\% (68/163) for those with 1, 2, and 3 or more follow-up visits, respectively. Baseline characteristics associated with higher attrition were: non-white, positive drug-abuse screen, lower depression/anxiety symptom severity, and younger age.

CONCLUSION Although remission rates are high in those with 3 or more followup visits after routine screening and treatment of depression, attrition from care is a significant issue adversely affecting outcomes.

Ann Fam Med 2019;17:326-335. https://doi.org/10.1370/afm.2418.

\section{INTRODUCTION}

M ajor Depressive Disorder (MDD) affects $5 \%$ to $10 \%$ of adults in the United States every year. ${ }^{1-3}$ One-half of the patients with MDD seen in medical settings are not recognized as having depression ${ }^{4,5}$ and only 1 in 5 receive adequate treatment. ${ }^{2,6}$ The growing concern for undetected and untreated depression in medical settings has led to the recommendations for universal screening for depression in general adult populations. ${ }^{7}$ In primary care settings, $5 \%$ to $10 \%$ patients suffer from MDD; 2 to 3 times more suffer from depressive symptoms that do not meet MDD diagnostic criteria. ${ }^{8}$ Universal screening of depression and follow-up assessments ${ }^{9}$ in medical clinics should ameliorate the problem of under-recognition of depression. Despite gradual improvement in screening rates since 2009 , only $3 \%$ of patients in a national survey of ambulatory care settings were screened for depression in 2015. ${ }^{10}$

Research over the last 2 decades has reduced the uncertainty regarding where and how to treat patients who screen positive for depression 
and are diagnosed with a depressive disorder. Primary care clinics are ideal for screening for depression and for managing those who screen positive." Depressed patients treated in primary care clinics have similar outcomes to those in psychiatric settings when identical systematic measurement-based care $(\mathrm{MBC})$ procedures are followed. ${ }^{12,13}$ The MBC approach includes (1) standardized assessment of symptoms, side effects, and treatment adherence ${ }_{i}(2)$ point-of-care decision-making for treatment ${ }_{i}$ (3) consistent follow-up visits; and (4) feedback to clinicians to assist decision making. Use of $\mathrm{MBC}$ is associated with rates of remission twice as high when compared with standard of care $^{14}$ and has now been adopted in treatment guidelines for depression. ${ }^{15}$ As clinicians rarely administer serial measurements in their practice, ${ }^{16-18}$ the $\mathrm{MBC}$ approach relies on patient self-report assessments for both screening and management of depression.

The paradigm of screening plus treatment initiation involves identification of patients who may not be seeking treatment for depression. Hence, the rates of treatment initiation maybe low and those of attrition may be high. Current estimates suggest that even among treatment-seeking depressed outpatients, over one-fourth drop out of care during initial acute-phase antidepressant treatment. ${ }^{19}$ Furthermore, adherence to prescribed antidepressant treatment may be an issue among those continuing in care. ${ }^{20}$ Finally, the outcome of antidepressant treatment in clinical settings is unknown, but estimates suggest that less than $6 \%$ of depressed patients attain remission in community settings. ${ }^{21}$

This report utilizes a sample of convenience to describe clinical outcomes of the first 25,000 patients screened for depression as part of an ongoing qualityimprovement project to improve the recognition and treatment of depression in 16 primary care clinics that predominantly serve uninsured or underinsured minority populations. This report describes the screening, diagnostic, and treatment recommendation steps, and the treatment outcomes over the 18 weeks following the screening visit for those who screened positive for depression from an observational cohort of patients seeking care in primary care clinics for nonmental health-related conditions.

This report is novel in describing a quality improvement project that incorporates health information technology advances to implement large-scale screening and treatment of depression. This study aimed to determine the following: (1) the proportion of patients in primary care settings that screen positive for depression, (2) the proportion of those with positive screens that were diagnosed with a depressive disorder, (3) the proportion of those diagnosed with a depressive disorder that initiated $\mathrm{MBC}$ treatment, underwent active surveillance, or were referred to an external specialist, (4) the proportion of those who were diagnosed with a depressive disorder that returned for a follow-up visit in the next 18 weeks, and (5) the proportion of those who initiated pharmacological treatment and attained symptomatic improvement with 1 or more follow-up visits during the following 18 weeks.

\section{METHODS}

This report is based on deidentified data obtained from the first 25,000 patients screened in an ongoing quality-improvement project for measurement-based MDD management. For each patient, the clinics created a profile in a web-based application that included limited demographic information along with self-report forms and clinician assessments. This report only includes data collected from August 2014 through November 2016 in the web-based application. The study was reviewed and approved by the Institutional Review Board of University of Texas Southwestern Medical Center at Dallas with a waiver of the need to obtain informed consent from individual patients.

\section{Quality-Improvement Project}

The quality-improvement project emphasizes depression as a chronic medical illness. It is centered on evidence-based practices for management of depression as the new standard of care in primary care practice, and can be augmented with behavioral health integration in primary care settings using collaborative care, colocation, teletherapy, etc. ${ }^{22,23}$ The project utilizes a point-of-care web-based application to (1) screen, (2) monitor depressive symptoms over time for patients who screen positive, and (3) guide the clinicians using MBC. The project requires all clinic staff to participate in up to 4 hours of face-to-face training that included didactic training on depression (prevalence, burden, comorbidity with medical disorders, and available treatment options using the MBC approach) and hands-on training with the web-based application. Before gaining access to the web-based application, clinicians (physicians, advanced practice nurses, or physician assistants) had to complete an additional 3 hours of online learning about treatment algorithms for management of depression. Members of the qualityimprovement project team provided ongoing assistance with technical or clinical questions and facilitated interactions with public mental health agencies around the metropolitan area for referrals.

\section{Clinical Sites}

Records from the 16 participating primary care clinics $(\mathrm{n}=25,000)$ included 6 charity clinics $(\mathrm{n}=9,947$, 
$39.8 \%)_{;} 6$ federally qualified health care centers $(\mathrm{n}=11,556,46.2 \%) ; 2$ private clinics serving lowincome population ( $\mathrm{n}=3,081,12.3 \%)$; and 2 private clinics serving patients with either Medicare or private insurance $(n=416,1.7 \%)$. Clinicians included physicians (internal medicine, family medicine, and pediatrics), physician assistants, and advanced practice nurses. Some clinics also had behavioral counselors available, either onsite $(2 / 16)$ or via teletherapy $(4 / 16) .{ }^{23,24}$ None of the clinics were systematically screening for depression before the initiation of quality-improvement project.

\section{Universal Screening for Depression}

All clinics administered the 2-item Patient Health Questionnaire (PHQ-2) self-report screen for depression. ${ }^{25}$ This scale rates sad mood and anhedonia each with a 0-3 score for a total score range of 0-6. A positive screen was defined as PHQ-2 score $>2,{ }^{26}$ due to high sensitivity (83\%) and specificity (92\%) for detecting MDD in primary care settings. ${ }^{27}$ The first 2 items of the patient health questionnaire for adolescents (PHQA) were used for patients aged 12 to 17 years. ${ }^{28}$ Positive screen resulted in additional assessments while negative screens were scheduled for rescreen in 1 year.

\section{Additional Assessment of Positive Screens}

The 9-item Patient Health Questionnaire (PHQ-9) is a self-report measure that assesses symptom pervasiveness in 9 symptom domains that define a major depressive episode. ${ }^{26}$ Each PHQ-9 item is scored from $0-3$, for a total score range of 0-27. Scores of 0-4, 5-9, 10-14, 15-19, and 20-27 are considered as minimal, mild, moderate, severe, and very severe symptom severity, respectively. ${ }^{26}$

The Generalized Anxiety Disorder 7-item scale (GAD-7) is a self-report measure of 7 symptom domains of generalized anxiety, each rated from 0-3 for a total score range of $0-21 .^{29}$

The Concise Associated Symptom Tracking SelfReport (CAST-SR) is a 16-item self-report measure that assesses symptom domains of irritability, anxiety, mania, insomnia, and panic with good reliability and validity. $^{30}$

The Pain Frequency Intensity and Burden Scale (P-FIBS) is a 4 -item self-report measure, each item rated from 0-8 for a total score range of 0-32, with strong construct validity and excellent internal consistency. ${ }^{31}$

The Alcohol and Drug Usage Screen consists of 2 single-item self-report questions to screen for alcohol use ("How many times in the past year have you had 5 or more drinks [for men, 4 or more drinks for women] in a day?") ${ }^{32}$ and drug use ("How many times in the past year have you used an illegal drug or used a pre- scription medication for nonmedical reasons?"), ${ }^{33}$ with responses $\geq 1$ considered as positive for each item.

The Frequency, Intensity, and Burden of Side Effect Rating Scale (FIBSER) is a 3 -item self-report measure with each item rated from 0-6, assessing overall frequency, intensity, and burden of side effects associated with antidepressant medications. ${ }^{34}$

The Patient Adherence Questionnaire (PAQ) is a 2 -item self-report questionnaire of adherence that asks about the number of days antidepressant medications were either missed or changed in the past 7 days. ${ }^{20}$

\section{Diagnostic Assessment}

Clinicians rendered their diagnoses based on a Diagnostic and Statistical Manual of Mental Disorders, 5 th edition, checklist included in the web-based application. Documentation options in the application included diagnoses of depressive disorders (major depressive disorder, adjustment disorder with depressed mood, persistent depressive disorder, and unspecified depressive disorder), other psychiatric disorders, ruled out all psychiatric disorders, or identified the need for additional follow-up.

\section{Follow-Up Options}

After the diagnostic assessment, clinicians could document their follow-up plan as (1) pharmacological treatment using $\mathrm{MBC}^{12}{ }_{i}(2)$ active surveillance with symptomatic monitoring using the PHQ-9, GAD-7, and CAST-SR (3) behavioral treatment from a licensed mental health clinician in the primary care setting ${ }_{i}(4)$ referral to an external clinic; or (5) no further follow-up, along with an option to document patient refusal.

\section{Pharmacological Treatment}

Patients completed assessments of symptoms (PHQ9, GAD-7, and CAST-SR), side effects (FIBSER), and adherence $(P A Q)$ at each visit. Clinicians were trained in the previously published ${ }^{12}$ and subsequently validated $^{14} \mathrm{MBC}$ algorithms and encouraged to discuss these assessments with their patients. Follow-ups were recommended every 2 weeks but occurred on the basis of patient preference and clinician availability. There was no restriction on prescribed medications.

\section{Statistical Analysis}

Three levels of data were available: those with PHQ-2 screen $(n=25,000)$, those with PHQ-2 positive screen $(\mathrm{n}=4,325)$, and those with a depressive disorder plus 18 -week enrollment before database closure $(n=2,160)$. The duration of 18 weeks was selected to capture 4 months of data reflecting the acute-phase course of antidepressant treatment. Baseline clinical and sociodemographic characteristics were compared using descriptive 
statistics in the full sample (positive vs negative screen); in those with positive screen results (using PHQ-9 severity groups ${ }^{26}$ ); and in those with depressive disorder plus 18 -week enrollment $(0,1,2$, and 3 or more follow-up visits). The impact of a number of follow-up visits on the likelihood of remission (last available PHQ-9 $<5$ within the 18 -week post-baseline period) were tested with $\chi^{2}$ tests using all available data.

\section{RESULTS}

From August 2014 through November 2016, 26,588 patients were offered PHQ-2 screening at 16 clinics and 25,000 agreed; 1,588 (6.0\%) declined the offered screening. Of those who agreed to screening, the majority were women and used the Spanish version of the PHQ-2, representing the patient population of these clinics (Table 1). The proportion of patients of the ages $12-17,18-65$, and $>65$ years were $6.99 \%(n=1,748), 87.40 \%(n=21,850)$, and $5.61 \%(n=1,402)$ respectively. The mean age of participants was 40.88 years, with a standard deviation (SD) of 15.52. Age was not significantly different between the negative- and positive-screened groups.

Patients in Primary Care Settings That Screened Positive for Depression Overall, 17.3\% (4,325/25,000) screened positive for depression (Figure 1), with rates at

\section{Figure 1. Rates of positive screen and diagnosis of depression in primary care patients.}

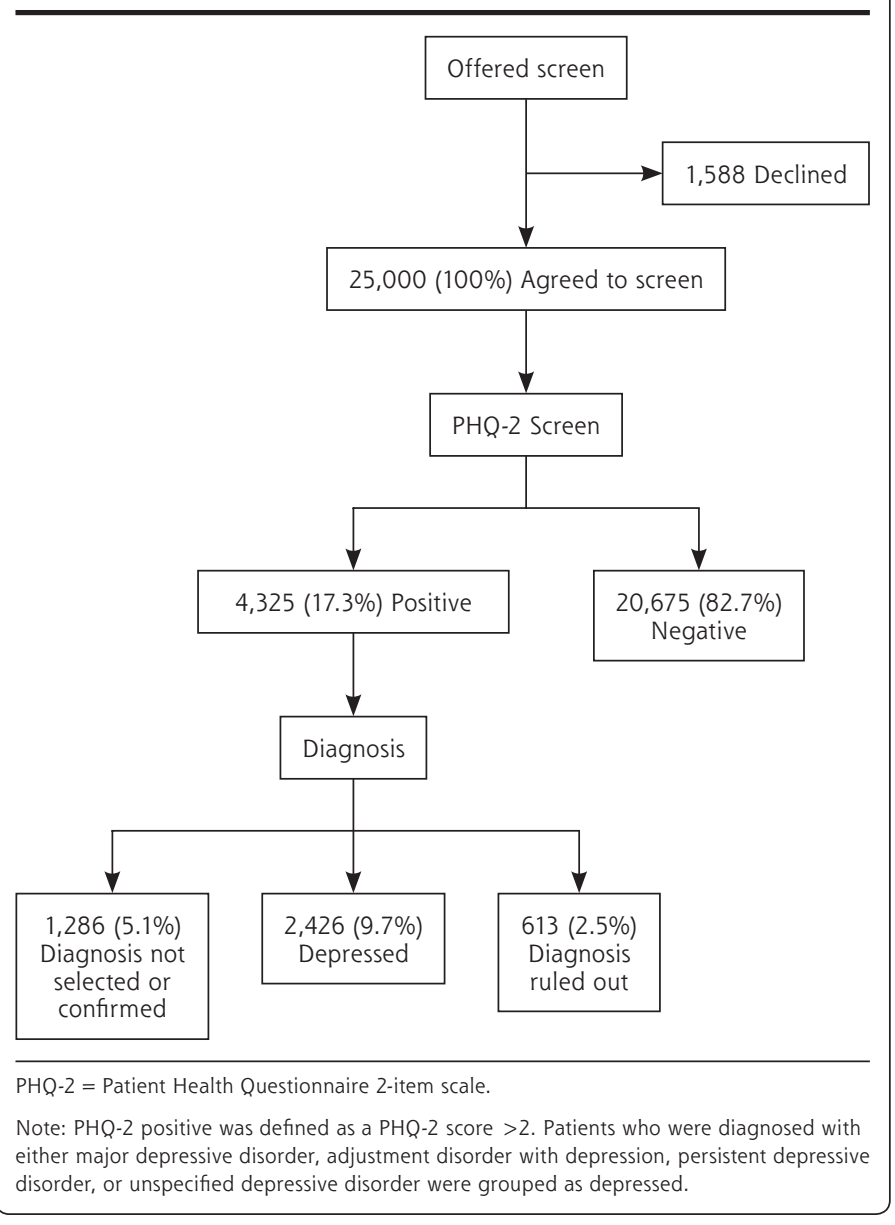

Table 1. Baseline Characteristics of Patients Screened in VitalSign6 Project

\begin{tabular}{|c|c|c|c|c|c|c|}
\hline \multirow[b]{2}{*}{ Characteristics } & \multirow{2}{*}{$\begin{array}{c}\text { Total } \\
(n=25,000) \\
\text { No. }\end{array}$} & \multirow{2}{*}{$\begin{array}{c}\text { PHQ-2 Negative } \\
\text { (n= 20,675), } \\
\text { No. }(\%)\end{array}$} & \multirow{2}{*}{$\begin{array}{c}\text { PHQ-2 Positive } \\
\text { (n=4,325), } \\
\text { No. }(\%)\end{array}$} & \multicolumn{2}{|c|}{ Positive vs Negative } & \multirow{2}{*}{$\begin{array}{c}\text { Missing Data, } \\
\text { No. }\end{array}$} \\
\hline & & & & $\chi^{2}(\mathrm{df})$ & $P$ Value & \\
\hline Sex & & & & $8.98(1)$ & 0.003 & 9,115 \\
\hline Female & 11,266 & $9,199(81.65)$ & $2,067(18.35)$ & & & \\
\hline Male & 4,619 & $3,864(83.65)$ & $755(16.35)$ & & & \\
\hline Language & & & & $229.05(1)$ & $<.001$ & 0 \\
\hline English & 11,770 & $9,282(78.86)$ & $2,488(21.14)$ & & & \\
\hline Spanish & 13,230 & $11,393(86.11)$ & 1,837 (13.89) & & & \\
\hline Race & & & & $149.39(3)$ & $<.001$ & 17,942 \\
\hline African American & 892 & $631(70.74)$ & $261(29.26)$ & & & \\
\hline White & 3,142 & $2,449(77.94)$ & $693(22.06)$ & & & \\
\hline $\begin{array}{l}\text { American Indian or } \\
\text { Native Alaskan }\end{array}$ & 312 & $228(73.08)$ & $84(26.92)$ & & & \\
\hline Other & 2,712 & $2,359(86.98)$ & $353(13.02)$ & & & \\
\hline Ethnicity & & & & $115.75(1)$ & $<.001$ & $17,724(70.9)$ \\
\hline Hispanic & 5,911 & $4,911(83.08)$ & $1,000(16.92)$ & & & \\
\hline Non-Hispanic & 1,365 & $960(70.33)$ & $405(29.67)$ & & & \\
\hline
\end{tabular}


Table 2. Baseline Characteristics of PHQ-2 Positive Patients by Depression Severity $(N=4,235)$

\begin{tabular}{|c|c|c|c|c|c|c|}
\hline \multirow[b]{2}{*}{ Characteristic } & \multicolumn{5}{|c|}{ Depression Severity } & \multirow[b]{2}{*}{$\begin{array}{c}\text { Missing } \\
\text { Data, No. }\end{array}$} \\
\hline & $\begin{array}{c}\text { Minimal } \\
(n=167), \\
\text { No. }(\%)\end{array}$ & $\begin{array}{c}\text { Mild } \\
(n=971) \\
\text { No. }(\%)\end{array}$ & $\begin{array}{c}\text { Moderate } \\
(n=1,257) \\
\text { No. }(\%)\end{array}$ & $\begin{array}{c}\text { Moderately Severe } \\
(n=1,084) \\
\text { No. }(\%)\end{array}$ & $\begin{array}{c}\text { Severe } \\
(n=846) \\
\text { No. (\%) }\end{array}$ & \\
\hline \multicolumn{7}{|l|}{ Categorical variables } \\
\hline \multicolumn{6}{|l|}{ Sex } & 1,503 \\
\hline Female & $69(3.3)$ & 407 (19.7) & $620(30.0)$ & $538(26.0)$ & $433(21.0)$ & \\
\hline Male & $41(5.4)$ & $191(25.3)$ & $219(29.0)$ & $170(22.5)$ & $134(17.8)$ & \\
\hline \multicolumn{6}{|l|}{ Language } & 0 \\
\hline English & $91(3.7)$ & $428(17.2)$ & $682(27.4)$ & $696(28.0)$ & $591(23.7)$ & \\
\hline Spanish & $76(4.1)$ & $543(29.6)$ & $575(31.3)$ & $388(21.1)$ & $255(13.9)$ & \\
\hline \multicolumn{6}{|l|}{ Race } & 2,934 \\
\hline African American & $18(6.9)$ & $45(17.2)$ & $71(27.2)$ & $64(24.5)$ & $63(24.1)$ & \\
\hline White & $18(2.6)$ & $170(24.5)$ & $217(31.3)$ & $161(23.2)$ & $127(21.1)$ & \\
\hline American Indian or Native Alaskan & $0(0.0)$ & $8(9.5)$ & $19(22.6)$ & $26(31.0)$ & $31(36.9)$ & \\
\hline Other & $20(5.7)$ & $90(25.5)$ & $108(30.6)$ & $76(21.5)$ & $59(16.7)$ & \\
\hline \multicolumn{6}{|l|}{ Ethnicity } & 2,920 \\
\hline Hispanic & $30(3.0)$ & $240(24.0)$ & $317(31.7)$ & $227(22.7)$ & $186(18.6)$ & \\
\hline Non-Hispanic & $16(4.0)$ & $64(15.8)$ & $103(25.4)$ & $110(27.2)$ & $112(27.7)$ & \\
\hline \multicolumn{6}{|l|}{ Diagnosis } & 0 \\
\hline Major depressive disorder & $2(0.1)$ & $184(9.8)$ & $499(26.5)$ & $628(33.3)$ & $571(30.3)$ & \\
\hline Adjustment disorder with depression & $1(0.7)$ & $52(37.7)$ & $47(34.1)$ & $24(17.4)$ & $14(10.1)$ & \\
\hline Persistent depressive disorder & $0(0.0)$ & $11(18.0)$ & $23(37.7)$ & $13(21.3)$ & $14(23.0)$ & \\
\hline Unspecified depressive disorder & $0(0.0)$ & $84(24.5)$ & $132(38.5)$ & $94(27.4)$ & $33(9.6)$ & \\
\hline No psychiatric disorder & $82(19.3)$ & $206(48.6)$ & $96(22.6)$ & $29(6.8)$ & $11(2.6)$ & \\
\hline Other psychiatric disorder & $3(1.6)$ & $36(19.1)$ & $55(29.1)$ & $56(29.6)$ & $39(20.6)$ & \\
\hline No diagnosis selected & $75(24.7)$ & $65(21.4)$ & $51(16.8)$ & $65(21.4)$ & $48(15.8)$ & \\
\hline Unable to confirm & $3(0.3)$ & $320(35.6)$ & $329(36.6)$ & $149(16.6)$ & $97(10.8)$ & \\
\hline Currently in treatment & $1(1.2)$ & $13(15.5)$ & $25(29.8)$ & $26(31.0)$ & $19(22.6)$ & \\
\hline \multicolumn{6}{|l|}{ Alcohol screen } & 2,102 \\
\hline Negative & $64(4.0)$ & 369 (22.9) & $465(28.8)$ & $382(23.6)$ & $335(20.7)$ & \\
\hline Positive & $13(2.1)$ & $95(15.6)$ & $178(29.3)$ & $174(28.6)$ & $148(24.4)$ & \\
\hline \multicolumn{6}{|l|}{ Drug use screen } & 2,102 \\
\hline Negative & $73(3.9)$ & $428(22.8)$ & $561(29.9)$ & $445(23.7)$ & $371(19.7)$ & \\
\hline Positive & $4(1.2)$ & $36(10.4)$ & $82(23.8)$ & $111(32.2)$ & $112(32.4)$ & \\
\hline Continuous variables & Mean (SD) & Mean (SD) & Mean (SD) & Mean (SD) & Mean (SD) & \\
\hline PHQ-9 & $3.43(0.5)$ & $7.29(1.4)$ & $11.99(1.4)$ & $16.9(1.4)$ & $22.65(2.1)$ & 0 \\
\hline GAD-7 & $1.74(2.8)$ & $5.4(4.1)$ & $9.16(4.6)$ & $12.84(4.8)$ & $16.93(4.1)$ & 383 \\
\hline P-FIBS & $5.47(7.1)$ & $11.11(8.9)$ & $13.64(8.9)$ & $16.41(9.3)$ & $19.03(9.3)$ & 2,019 \\
\hline Age & $41.93(17.8)$ & $40.43(15.6)$ & $41.02(15.1)$ & $41.2(14.7)$ & 41.06 (13.9) & 0 \\
\hline \multicolumn{7}{|c|}{$\begin{array}{l}\text { PHQ-2 = Patient Health Questionnaire 2-item; PHQ-9 = Patient Health Questionnaire 9-item; GAD-7 = generalized anxiety disorder 7-item scale; P-FIBS = pain frequency } \\
\text { intensity, and burden scale. }\end{array}$} \\
\hline \multicolumn{7}{|c|}{$\begin{array}{l}\text { Notes: Severity of depression }{ }^{26} \text { was defined using PHQ-9 as minimal }(0-4) \text {, mild (5-9), moderate (10-14), moderately severe (15-19), and severe (20-27). Alcohol }{ }^{32} \text { and } \\
\text { drug use }{ }^{33} \text { during the past year were screened with self-report measures. }\end{array}$} \\
\hline
\end{tabular}

individual clinics ranging from $6.7 \%$ to $25.5 \%$ (Supplementary Figure 1, http://www.annfammed.org/content/17/4/326/supp1/DC1). Higher positive screen rates were noted in those using the English language (21.1\%) and being of non-Hispanic (29.7\%) ethnicity (Table 1). The average PHQ-9 score for those with a positive screen was $13.92(\mathrm{SD}=5.89)$. Of those with a positive screen, $75.3 \%$ had moderate-to-severe depressive symptom severity (Table 2).
Positive Screen Patients Diagnosed With a Depressive Disorder

Clinicians diagnosed $56.1 \%(2,426 / 4,325)$ of positive screens with a depressive disorder (Figure 1) with $\operatorname{MDD}(77.7 \%, 1,884 / 2,426)$ being the most common and persistent depressive disorder $(2.5 \%, 61 / 2,426)$ being the least common. Only $1.9 \%(84 / 4,325)$ of positive screens were in treatment before the initiation of quality improvement project. Clinical and sociodemo- 
graphic variables including diagnoses of depressive disorder and rates of drug and alcohol use screens based on PHQ-9 symptom severity levels of positive screens are presented in Table 2.

\section{Diagnosed Patients That Were Treated, Monitored,} or Referred

Of the 2,160 depressed patients who enrolled at least 18 weeks before database closure, only $6.4 \%$ were referred out for external specialty care, whereas $64.8 \%$ were started on pharmacotherapy using MBC. See Figure 2 for rates of active surveillance, nonpharmacological treatment, no further follow-up indicated, and treatment refusals.

\section{Diagnosed Patients That Returned for a Follow-up Visit}

Of those with $\geq 18$-week data $(n=2,160), 52.0 \%$ did not return for even a single visit following a positive screen, and only $9.3 \%$ returned for $\geq 3$ follow-up visits (Table 3). The mean (SD) days to first follow-up visit following the initial screen/diagnostic visit was 50.8 (32.4) days for those with only 1 follow-up visit, 33.2 (21.0) days for those with 2 follow-up visits, and 22.0 (14.8) days for those with $\geq 3$ follow-up visits. Depressed patients with more follow-up visits reported higher baseline levels of depressive and anxious symptoms (Table 3 ). More patients returned after pharmacotherapy was selected and initiated (54.5\%, $763 / 1,400)$ than after psychotherapy was selected $\left(36.6 \%, 82 / 224, \chi^{2}(1)=27.77, P<.0001\right)$. Of those initiated in pharmacotherapy using measurement-based care $(n=1,400), 45.5 \%$ did not return for even a single follow-up visit, while $30.2 \%, 12.6 \%$, and $11.6 \%$ returned for 1,2 , and for $\geq 3$ follow-up visits, respectively, over the 18 -weeks period.
Patients With Pharmacological Treatment That Attained Symptomatic Improvement

Figure 3 shows the remission rates of depressed patients who were treated with pharmacotherapy using $\mathrm{MBC}$ and had 1, 2, and $\geq 3$ follow-up visits. Among those with at least 1 follow-up visit $(n=763)$, remission rates were higher for those with $\geq 3$ follow-up visits $\left(\chi^{2}(2)=28.94, P<.0001\right)$ than those with 1 or 2 visits.

\section{DISCUSSION}

Screening for depression with PHQ-2 was widely accepted in this observational cohort of 25,000 patients from 16 primary care clinics. The PHQ-2 positive screen rate was $17 \%$. Diagnoses were rendered at the screening visit for three-quarters of the screen-positive patients. Of those who screened positive, $56.1 \%$ were given a depressive disorder diagnosis Clinicians failed to document or select a diagnosis for $7.0 \%$, and were unable to confirm a diagnosis in $20.8 \%$ of screen-positive patients. In both of these groups, most $(63 \%$ to $75 \%)$ patients scored less than 15 on the PHQ-9. The remission rates for patients with $\geq 3$ and $\geq 1$ follow-up visits were $41.7 \%$ and $27.5 \%$ respectively. These rates were comparable to the large-scale Sequenced Treatment Alternatives to Relieve Depression $\left(\mathrm{STAR}^{*} \mathrm{D}\right)$ study $(27.5 \%$ remission rate after level 1 based on Hamilton Rating Scale for Depression severity), ${ }^{12}$ and superior to the reported remission rate of $15 \%$ with first antidepressant treatment in psychiatric practices at large academic centers. ${ }^{35}$

The rates of PHQ-2 screen positive (17\%) patients with depressive diagnoses (10\%) and MDD (7.5\%) are comparable to other primary care studies, ${ }^{9,36}$ as is the false positive rate $(14.2 \%$; depression was ruled out in $632 / 4,325$ positive screens) from the PHQ-2. ${ }^{18}$

\section{Figure 2. Selection of treatment plan for depressed outpatients enrolled for at least 18 weeks of study.}

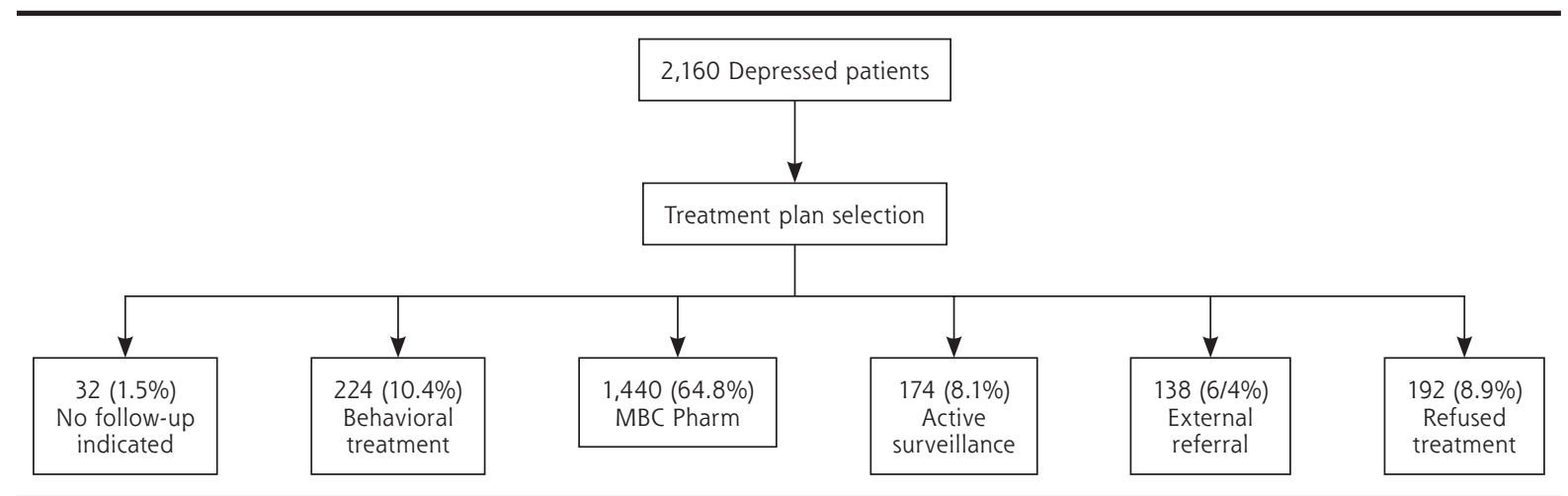

MBC Pharm = Pharmacotherapy prescribed by the primary care provider using measurement-based care approach.

Note: Treatment was selected by the primary care providers for depressed patients diagnosed as having either major depressive disorder, adjustment disorder with depression, persistent depressive disorder, or unspecified depressive disorder. 
Table 3. Baseline Characteristics by Number of Follow-Up Visits $(N=2,160)$

\begin{tabular}{|c|c|c|c|c|c|c|c|c|c|}
\hline \multirow[b]{2}{*}{ Characteristic } & \multicolumn{4}{|c|}{ Follow-Up Visits, No. (\%) } & \multicolumn{2}{|c|}{ Overall } & \multicolumn{2}{|c|}{$\begin{array}{c}\text { Follow-Up } \\
\text { Visits: } 0 \text { vs } \geq 1\end{array}$} & \multirow[b]{2}{*}{$\begin{array}{l}\text { Missing } \\
\text { Data, No }\end{array}$} \\
\hline & $\begin{array}{c}0 \\
(n=1,123)\end{array}$ & $\begin{array}{c}1 \\
(n=612)\end{array}$ & $\begin{array}{c}2 \\
(n=225) \\
\end{array}$ & $\begin{array}{c}\geq 3 \\
(n=200)\end{array}$ & $x^{2}$ & $\begin{array}{c}P \\
\text { Value }\end{array}$ & $x^{2}$ & $\begin{array}{c}P \\
\text { Value }\end{array}$ & \\
\hline \multicolumn{10}{|l|}{ Categorical variables } \\
\hline Sex & & & & & 2.89 & .41 & 0.15 & .70 & 814 \\
\hline Female & $524(50.7)$ & $274(26.5)$ & $113(10.9)$ & $123(11.9)$ & & & & & \\
\hline Male & $162(51.9)$ & $91(29.2)$ & $25(8.0)$ & $34(10.9)$ & & & & & \\
\hline Language & & & & & 0.98 & .81 & 0.09 & .76 & 0 \\
\hline English & $683(52.3)$ & $375(28.7)$ & $130(9.9)$ & $119(9.1)$ & & & & & \\
\hline Spanish & $440(51.6)$ & $237(27.8)$ & $95(11.1)$ & $81(9.5)$ & & & & & \\
\hline Race & & & & & 39.68 & $<.001$ & 22.73 & $<.001$ & 1,471 \\
\hline African American & $74(49.3)$ & $46(30.7)$ & $17(11.3)$ & $13(8.7)$ & & & & & \\
\hline White & $168(45.9)$ & $93(25.4)$ & $57(15.6)$ & $48(13.1)$ & & & & & \\
\hline $\begin{array}{l}\text { American Indian or } \\
\text { Native Alaskan }\end{array}$ & $20(58.8)$ & $10(29.4)$ & $0(0.0)$ & $4(11.8)$ & & & & & \\
\hline Other & $96(69.1)$ & $33(23.7)$ & $8(5.8)$ & $2(1.4)$ & & & & & \\
\hline Ethnicity & & & & & 3.42 & .33 & 0.66 & .42 & 1,436 \\
\hline Hispanic & $233(46.5)$ & $123(24.5)$ & $67(13.4)$ & $78(15.6)$ & & & & & \\
\hline Non-Hispanic & $111(49.8)$ & $62(27.8)$ & $23(10.3)$ & $27(12.1)$ & & & & & \\
\hline Alcohol screen & & & & & 2.49 & .48 & 0.02 & .89 & 1,080 \\
\hline Negative & $423(53.3)$ & $204(25.7)$ & $78(9.8)$ & $89(11.2)$ & & & & & \\
\hline Positive & $151(52.8)$ & $75(26.2)$ & $21(7.3)$ & $39(13.6)$ & & & & & \\
\hline Drug screen & & & & & 4.23 & .24 & 3.91 & .05 & 1,080 \\
\hline Negative & $478(51.9)$ & $243(26.4)$ & $86(9.3)$ & $114(12.4)$ & & & & & \\
\hline Positive & $96(60.4)$ & $36(22.6)$ & $13(8.2)$ & $14(8.8)$ & & & & & \\
\hline Follow-up & & & & & 105.24 & .0001 & 3.81 & $<.06$ & 0 \\
\hline MBC Pharm T/t & $637(45.5)$ & $423(30.2)$ & $177(12.6)$ & $163(11.6)$ & & & & & \\
\hline Behavioral T/t & $142(63.4)$ & $44(19.6)$ & $16(7.2)$ & $22(9.8)$ & & & & & \\
\hline Active Surveillance & $113(64.9)$ & $45(25.9)$ & $9(5.2)$ & $7(4.0)$ & & & & & \\
\hline No follow-up & $27(84.4)$ & $3(9.4)$ & $2(6.2)$ & $0(0.0)$ & & & & & \\
\hline External Referral & $94(68.1)$ & $37(36.8)$ & $4(2.9)$ & $3(2.2)$ & & & & & \\
\hline Refused T/t & $110(57.3)$ & $60(31.3)$ & $17(8.8)$ & $5(2.6)$ & & & & & \\
\hline Continuous variables & Mean (SD) & Mean (SD) & Mean (SD) & Mean (SD) & $\mathbf{F}$ & $\begin{array}{c}P \\
\text { Value }\end{array}$ & $\mathbf{F}$ & $\begin{array}{c}P \\
\text { Value }\end{array}$ & \\
\hline PHQ-9 & $\begin{array}{l}15.33 \\
(5.46)\end{array}$ & $\begin{array}{l}15.82 \\
(5.38)\end{array}$ & $\begin{array}{l}16.76 \\
(5.23)\end{array}$ & $\begin{array}{l}17.15 \\
(4.90)\end{array}$ & 9.46 & $<.001$ & 25.45 & $<.001$ & 0 \\
\hline GAD-7 & $\begin{array}{l}11.93 \\
(5.76)\end{array}$ & $\begin{array}{l}11.98 \\
(5.90)\end{array}$ & $\begin{array}{l}12.74 \\
(5.48)\end{array}$ & $\begin{array}{l}13.7 \\
(5.24)\end{array}$ & 6.15 & $<.001$ & 10.73 & .001 & 142 \\
\hline P-FIBS & $\begin{array}{l}16.5 \\
(9.44)\end{array}$ & $\begin{array}{l}15.81 \\
(9.53)\end{array}$ & $\begin{array}{l}17.67 \\
(8.58)\end{array}$ & $\begin{array}{l}14.98 \\
(9.29)\end{array}$ & 1.94 & .13 & 0.37 & .55 & 1,044 \\
\hline Age & $\begin{array}{l}41.72 \\
(14.78)\end{array}$ & $\begin{array}{c}43.53 \\
(14.58)\end{array}$ & $\begin{array}{l}43.95 \\
(12.56)\end{array}$ & $\begin{array}{l}42.61 \\
(13.04)\end{array}$ & 2.92 & .04 & 6.12 & .02 & 0 \\
\hline
\end{tabular}

Patient attrition was high; over one-half the patients diagnosed with a depressive disorder did not return for even a single follow-up visit, and less than 1 in 10 had $\geq 3$ follow-up visits. The attrition rate in this cohort of patients who were identified by depression screening and were not seeking treatment was substantially higher than the STAR*D study and what has been typically reported in the general medical sector. ${ }^{19,33}$
Even in a recently reported randomized clinical trial of treatment-seeking depressed patients, 1 in 3 dropped out if they were randomized to a nonpreferred treatment. ${ }^{37}$ Those less likely to return for even 1 visit following the screen were younger, of minority status (ethnic or racial), less severely depressed, and reported drug use; findings that are consistent with the STAR*D study and other reports. ${ }^{19}$ Lower rates of positive 
screens in Hispanic patients and in those preferring the Spanish version of PHQ-2 are consistent with epidemiological studies. ${ }^{38}$ Furthermore, among the screenpositive patients, those using Spanish language and of Hispanic ethnicity had lower PHQ-9 scores.

Even among those patients who returned for 1 or 2 follow-up visits, the time since first visit was too long ( 5 to 7 weeks) to adequately make dose adjustments or manage side effects. Thus, the outcomes achieved do not represent those of carefully delivered $\mathrm{MBC}$ which entails diligently making dose adjustments, minimizing side-effects, and promoting adherence. Potential causes for the failure to implement MBC include the patient's unwillingness to engage, inadequate patient or clinician time for collaborative shared decision making, inadequate time for scheduling the next appointment, clinician's belief that the initial dose is the final dose and that dose adjustment is not needed, other administrative and attitudinal obstacles, or a combination of these and other factors.

It is critical to remedy attrition, especially from a public health perspective, as mental or physical health outcomes cannot be assessed in patients who do not engage in care. Thus, additional research is needed to elucidate the reasons for attrition (ie, child care needs, insurance loss, family stressors, job changes, lack of telephone access to receive reminder calls, and provider shortage) and implement means to mitigate attrition. Prior research has suggested several mechanisms to improve patient retention, including reminder phone

\section{Figure 3. Outcomes of depressed patients treated with pharmacotherapy with any follow-up visits.}

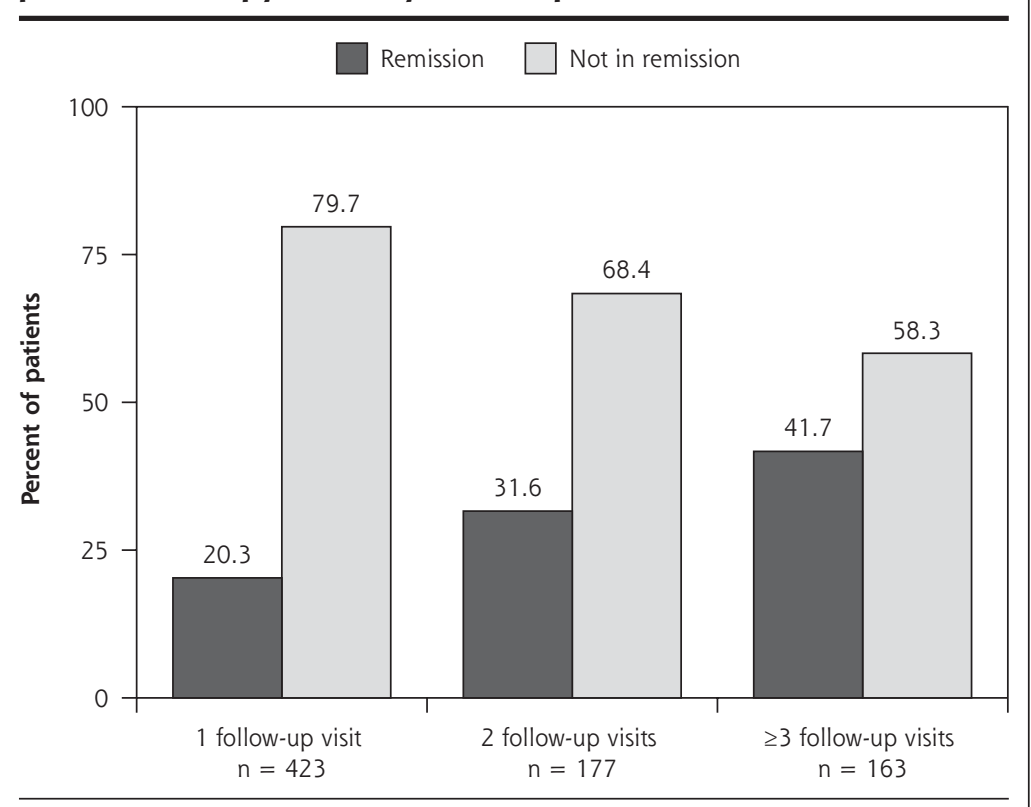

Note: Remission was defined as a score of $<5$ on the Patient Health Questionnaire 9-item scale. calls and letters (including automated telephone communication systems), ${ }^{39}$ small incentives like toys, food, or bus fare, ${ }^{40}$ and walk-in appointments. ${ }^{41}$ Current and future efforts to address some of these issues are detailed below as take-away lessons.

Regarding the recommended treatment options, 2 of 3 patients with a depressive disorder were started on pharmacotherapy using MBC, while behavioral psychotherapy treatment was recommended for 1 in 8 depressed patients. Only 1 in 16 patients with a depressive disorder was referred out, and less than 1 in 10 refused treatment. There was a higher rate of return for follow-ups after the screening visit for those recommended pharmacotherapy (54.5\%) compared with those for whom behavioral treatment was recommended (36.6\% return rate after screen).

This study has several limitations. Sociodemographic and other data were commonly missing from the clinics data. Additionally, details that were not systematically collected include percentage of patients missed from screening or follow-up assessments, alternative diagnoses in screen-positive patients in whom depression was ruled out, types of medication prescribed and behavioral treatments instituted, insurance status, and provider staffing. This limits the exploration of these important covariates on screening and treatment outcomes. The observational nature of study does not allow us to draw inferences about causality. Generalizability of these findings is also limited because of the lower socioeconomic status and predominantly minority status of patients. These clinics had few resources and were working against a substantial time obstacle, likely precluding adequate time for many patients at the clinic visits. Future studies are needed to devise optimal methods to engage providers in the use of the algorithm, diagnoses, and follow-up plans.

\section{Takeaway Lessons}

The first takeaway lesson from this evaluation is about the need for greater efforts to educate and engage with patients in treatment to reduce attrition. There may be a need to develop technological solutions, such as a patient-facing application or interactive voice response system, that allows patients to directly enter their health information and/ or interact with clinicians before and between scheduled clinic visits at 
regular intervals. Further, integration of the web-based application with the EHR to facilitate real-time 2-way information exchange is needed to allow easier documentation, fewer missing data, and perhaps greater buy-in from the clinics and practice managers. Such an integration may also allow accurate estimates of screening rates, fidelity to $\mathrm{MBC}$ approach, and the potential effects of clinical and sociodemographic variables on screening and treatment outcomes. Finally, it is possible that patients are more likely to stay in treatment if they receive their care preference, so more time spent engaging patients, especially those less educated, and investing in shared decision making may increase patient retention. Retention in treatment can also be improved by implementation of patient navigation, a process in which patients receive frequent reminders and follow-up calls and are connected with psychosocial resources to cope with financial, job, and personal stressors that may affect care retention. ${ }^{42}$ Additionally, pharmacological management using a MBC approach can be augmented with psychotherapy (such as behavioral activation) using teletherapy. ${ }^{23}$ Finally, a patient-centered medical management approach that integrates psychoeducational, behavioral, cognitive, interpersonal, and dynamic tools is needed for early identification and effective management of depression in primary care clinics to minimize attrition and non-adherence, and promote remission and functional recovery. ${ }^{43}$

In conclusion, this study demonstrated a structured approach to implement routine screening for depression and measurement-based treatment of patients in primary care clinics. Better patient engagement and retention and provision of adequately frequent visits to allow timely treatment adjustments are issues to be addressed for effective management of depression in primary care clinics.

To read or post commentaries in response to this article, see it online at http://www.AnnFamMed.org/content/17/4/326.

Submitted July 18, 2018; submitted, revised February 15, 2019; accepted March 12, 2019.

Key words: primary care issues; depression; measurement-based care; quality improvement; health care delivery/HSR; quality of care; primary health care, major depressive disorder, antidepressants, loss to follow-up

Author affiliations: Center for Depression Research and Clinical Care, UT Southwestern Medical Center, Dallas, Texas (Jha, Granneman, Trombello, Clark, Eidelman, Greer, Trivedi); Departments of Psychiatry and Neuroscience, Icahn School of Medicine at Mount Sinai, New York, New York (Jha); Duke-National University of Singapore, Singapore (Rush); Department of Psychiatry, Duke Medical School, Durham, North Carolina (Rush); Texas Tech University-Health Sciences Center, Permian Basin, Texas (Rush)
Funding support: This report was funded by Center for Depression Research and Clinical Care, The Rees-Jones Foundation (Trivedi, MH - PI), the Meadows Foundation, and the Hersh Foundation (Trivedi, $\mathrm{MH}-\mathrm{PI}$ ).

Acknowledgments: The authors thank the participants, families, staff, and colleagues who made this project possible, as well as Jeremy A. Kee, MA, for his editorial and administrative assistance in the production of this manuscript. Bruce D. Grannemann, MA, sadly, died in the course of this project, but his efforts, energy, and dedication were invaluable for the research.

The VitalSign ${ }^{6}$ program was funded in part by the Center for Depression Research and Clinical Care (CDRC), the Rees-Jones Foundation, the Meadows Foundation, and the Hersh Foundation. The content is solely the responsibility of the authors and does not necessarily represent the official views of the various funding organizations.

Disclaimer: The Intellectual Property of VitalSign ${ }^{6}$ belongs to the University of Texas Southwestern Medical Center (Principal Investigator, Dr Trivedi). All proprietary tools and methods used in VitalSign ${ }^{6}$ are owned by the University of Texas Southwestern Medical Center. While there currently are no plans, the University of Texas Southwestern Medical Center reserves the right to commercialize VitalSign ${ }^{6}$ in the future.

Supplemental Materials: Available at http://www.AnnFamMed. org/content/17/4/326/suppl/DC1/.

\section{References}

1. Hasin DS, Goodwin RD, Stinson FS, Grant BF. Epidemiology of major depressive disorder: results from the National Epidemiologic Survey on Alcoholism and Related Conditions. Arch Gen Psychiatry. 2005;62(10):1097-1106.

2. Kessler RC, Berglund P, Demler O, et al; National Comorbidity Survey Replication. The epidemiology of major depressive disorder: results from the National Comorbidity Survey Replication (NCS-R). JAMA. 2003;289(23):3095-3105.

3. Hasin DS, Sarvet AL, Meyers JL, et al. Epidemiology of adult DSM-5 major depressive disorder and its specifiers in the United States. JAMA Psychiatry. 2018;75(4):336-346.

4. Pignone M, Gaynes BN, Rushton JL, et al, U.S. Preventive Services Task Force Evidence Syntheses, formerly Systematic Evidence Reviews. Screening for Depression. Rockville, MD: Agency for Healthcare Research and Quality; 2002.

5. Coyne JC, Schwenk TL, Fechner-Bates S. Nondetection of depression by primary care physicians reconsidered. Gen Hosp Psychiatry. 1995; 17(1):3-12.

6. Young AS, Klap R, Sherbourne CD, Wells KB. The quality of care for depressive and anxiety disorders in the United States. Arch Gen Psychiatry. 2001;58(1):55-61.

7. Siu AL, Bibbins-Domingo K, Grossman DC, et al; US Preventive Services Task Force (USPSTF). Screening for depression in adults: US Preventive Services Task Force recommendation statement. JAMA. 2016;315(4):380-387.

8. Katon W, Schulberg H. Epidemiology of depression in primary care. Gen Hosp Psychiatry. 1992;14(4):237-247.

9. Mitchell AJ, Vaze A, Rao S. Clinical diagnosis of depression in primary care: a meta-analysis. Lancet. 2009;374(9690):609-619.

10. Bhattacharjee S, Goldstone L, Vadiei N, Lee JK, Burke WJ. Depression screening patterns, predictors, and trends among adults without a depression diagnosis in ambulatory settings in the United States. Psychiatr Serv. 2018;69(10):1098-1100.

11. Rush AJ. Clinical practice guidelines. Good news, bad news, or no news? Arch Gen Psychiatry. 1993;50(6):483-490. 
12. Trivedi MH, Rush AJ, Wisniewski SR, et al; STAR*D Study Team. Evaluation of outcomes with citalopram for depression using measurement-based care in STAR*D: implications for clinical practice. Am J Psychiatry. 2006;163(1):28-40.

13. Gaynes BN, Warden D, Trivedi MH, Wisniewski SR, Fava M, Rush AJ. What did STAR*D teach us? Results from a large-scale, practical, clinical trial for patients with depression. Psychiatr Serv. 2009; 60(11):1439-1445.

14. Guo T, Xiang YT, Xiao L, et al. Measurement-Based care versus standard care for major depression: a randomized controlled trial with blind raters. Am J Psychiatry. 2015;172(10):1004-1013.

15. Gelenberg AJ, Freeman MP, Markowitz JC, et al. Practice guideline for the treatment of patients with major depressive disorder, third edition. Am J Psychiatry. 2010;167(10):1.

16. Lewis CC, Scott K, Marti CN, et al. Implementing measurementbased care (iMBC) for depression in community mental health: a dynamic cluster randomized trial study protocol. Implement Sci. 2015;10(1):127.

17. Bickman L, Rosof-Williams J, Salzer MS, et al. What information do clinicians value for monitoring adolescent client progress and outcomes? Prof Psychol Res Pr. 2000;31(1):70-74.

18. Garland AF, Kruse M, Aarons GA. Clinicians and outcome measurement: what's the use? J Behav Health Serv Res. 2003;30(4):393-405.

19. Warden D, Trivedi MH, Wisniewski SR, et al. Predictors of attrition during initial (citalopram) treatment for depression: a STAR*D report. Am J Psychiatry. 2007;164(8):1189-1197.

20. Warden D, Trivedi MH, Carmody T, et al. Adherence to antidepressant combinations and monotherapy for major depressive disorder: a CO-MED report of measurement-based care. J Psychiatr Pract. 2014;20(2):118-132.

21. Pence BW, O'Donnell JK, Gaynes BN. The depression treatment cascade in primary care: a public health perspective. Curr Psychiatry Rep. 2012;14(4):328-335.

22. Michelle A. Blackmore, Kelly E. Carleton, Sarah M. Ricketts, et al. Comparison of collaborative care and colocation treatment for patients with clinically significant depression symptoms in primary care. Psychiatric Services.0(0):appi.ps.201700569.

23. Trombello JM, South C, Cecil A, et al. Efficacy of a behavioral activation teletherapy intervention to treat depression and anxiety in primary care VitalSign6 program. Prim Care Companion CNS Disord. 2017;19(5):17m02146.

24. Trombello JM, Trivedi MH. E-Behavioral Activation in Primary Care for Depression: A Measurement-Based Remission-Focused Treatment. New York, NY: Guilford Press; 2018.

25. Löwe B, Kroenke K, Gräfe K. Detecting and monitoring depression with a two-item questionnaire (PHQ-2). J Psychosom Res. 2005; 58(2):163-171.

26. Kroenke K, Spitzer RL, Williams JBW. The PHQ-9: validity of a brief depression severity measure. J Gen Intern Med. 2001;16(9):606-613.

27. Kroenke K, Spitzer RL, Williams JB. The Patient Health Questionnaire-2: validity of a two-item depression screener. Med Care. 2003;41(11):1284-1292.

28. Johnson JG, Harris ES, Spitzer RL, Williams JB. The patient health questionnaire for adolescents: validation of an instrument for the assessment of mental disorders among adolescent primary care patients. The Journal of adolescent health: official publication of the Society for Adolescent Medicine. 2002;30(3):196-204.
29. Spitzer RL, Kroenke K, Williams JB, Löwe B. A brief measure for assessing generalized anxiety disorder: the GAD-7. Arch Intern Med. 2006;166(10):1092-1097.

30. Trivedi MH, Wisniewski SR, Morris DW, et al. Concise Associated Symptoms Tracking scale: a brief self-report and clinician rating of symptoms associated with suicidality. J Clin Psychiatry. 2011;72(6): 765-774.

31. dela Cruz AM, Bernstein IH, Greer TL, et al. Self-rated measure of pain frequency, intensity, and burden: psychometric properties of a new instrument for the assessment of pain. J Psychiatr Res. 2014;59: 155-160.

32. Smith PC, Schmidt SM, Allensworth-Davies D, Saitz R. Primary care validation of a single-question alcohol screening test. J Gen Intern Med. 2009;24(7):783-788.

33. Smith PC, Schmidt SM, Allensworth-Davies D, Saitz R. A singlequestion screening test for drug use in primary care. Arch Intern Med. 2010;170(13):1155-1160.

34. Wisniewski SR, Rush AJ, Balasubramani GK, Trivedi MH, Nierenberg $A A ; S T A R * D$ Investigators. Self-rated global measure of the frequency, intensity, and burden of side effects. J Psychiatr Pract. 2006; 12(2):71-79.

35. Perlis RH, losifescu DV, Castro VM, et al. Using electronic medical records to enable large-scale studies in psychiatry: treatment resistant depression as a model. Psychol Med. 2012;42(1):41-50.

36. Pignone MP, Gaynes BN, Rushton JL, et al. Screening for depression in adults: a summary of the evidence for the U.S. Preventive Services Task Force. Ann Intern Med. 2002;136(10):765-776.

37. Boadie W. Dunlop, Mary E. Kelley, Vivianne Aponte-Rivera, et al. Effects of patient preferences on outcomes in the predictors of remission in depression to individual and combined treatments (PReDICT) study. Am J Psychiatry. 2017;0(0):appi.ajp.2016.16050517.

38. Margarita Alegría PD, Glorisa Canino PD, Patrick E. Shrout PD, et al. Prevalence of mental illness in immigrant and non-immigrant U.S. Latino groups. Am J Psychiatry. 2008;165(3):359-369.

39. Posadzki P, Mastellos N, Ryan R, et al. Automated telephone communication systems for preventive healthcare and management of long-term conditions. Cochrane Database Syst Rev. 2016;12: CD009921.

40. Lefforge NL, Donohue B, Strada MJ. Improving session attendance in mental health and substance abuse settings: a review of controlled studies. Behav Ther. 2007;38(1):1-22.

41. Molfenter T. Reducing appointment no-shows: going from theory to practice. Subst Use Misuse. 2013;48(9):743-749.

42. Howe-Martin L, Jester B, Walker R, et al. A pilot program for implementing mental health screening, assessment, and navigation in a community-based cancer center. Psychooncology. 2018;27(2): 683-686.

43. Rush AJ, Thase ME. Improving outcome of depression by patient-centered medical management (PCMM). Am J Psychiatry. 2018;175(12):1187-1198. 